\title{
Numerical Prediction of a Radial Turbine Performance Designed for Automotive engines Turbocharger
}

\author{
Layth H. Jawad \\ Department of Mechanical Techniques, Kerbala Technical Institute, \\ Al-Furat Al-Awsat Technical University,56001 Kerbala, Iraq \\ laihasan@yahoo.com
}

\begin{abstract}
These days the turbocharging system is assuming an essential part in enhancing car engines performance and diminishing fuel utilization and the fumes emanations, in spark-ignition and compression ignition engines. The performance of a radial turbine for the turbocharger device is heavily affected by the flow dynamics in a radial impeller. Furthermore, modification and improvement of a radial turbine impeller is a challenging task for turbomachinery engineers. Hence, this study aimed to further computational fluid dynamic analyses of a radial turbine stage performance .The design characteristics of a radial turbine stage, was used to simulate the flow by using independent packages of ANSYS CFX. The comparative study of a three dimensional flow simulation will give a more reasonable results of the turbine stage flow behavior and computational fluid dynamic simulation can give a more detailed result and reveal unexpected flow behavior like separation and vortexes.The results showed that the fluid flow dynamics within a turbine stage has indicated a noticeable performance characteristics. Obviously, it was observed that the pressure ratio and volume flow rate and efficiency were predicted numerically. Overall numerical results obtained from computational fluid dynamic simulations could produce a highly reliable for estimation on the performance a radial turbine of turbocharger.
\end{abstract}

Keywords: - Turbochrger; Radial Turbine; Vaned Nozzle; CFD.

في الوقت الحاضر تقنية الثناحن التوربيني يلعب دوراً أساسيا في تحسين أداء محركات السيارات، وتخفيض استهلاك الوقود

و انبعاثات العادم، في محركات الكازولين والديزل. أداء التوربين الثعاعي لجهاز الثناحن التوربيني يتأثز بشدة بديناميكية الجريان في التياتي

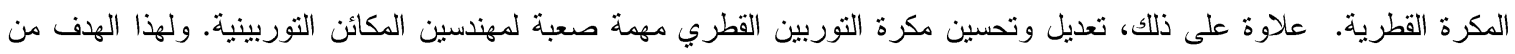

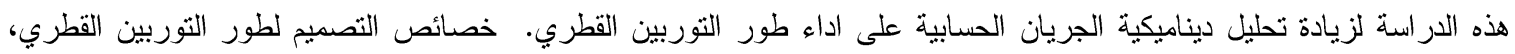

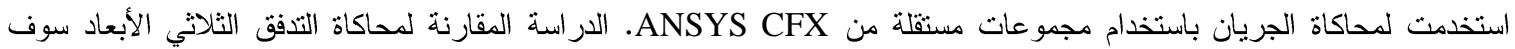

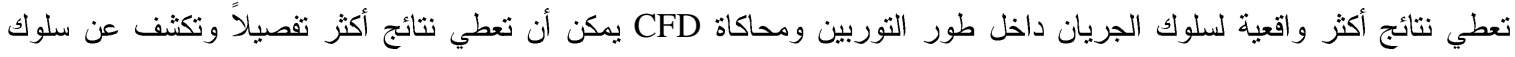
الجريان غير متوقعة مثل انفصال الجريان والدوامات. أظهرت النتائج أن ديناميكية جريان المائع داخل طور التوربين بينت بثكل

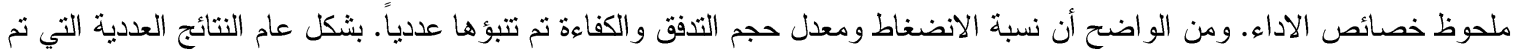
الحصول عليها من محاكاة ديناميكية الجريان الحسابية يمكن ان تقدم درجة عالية من الدقة لتخمين اداء التوربين القطري للثناصن التوربيني. الكلمات المفتاحية : - الثناحن التوربيني ؛ الثوريبنات شعاعي ؛ فو هه فأناد ؛CFD .

\section{Nomenclature}

CFD Computational Fluid dynamics

CAD Computer Aid Design

IGES Initial Graphics Exchange Specification

TE Trailing Edge

LE Leading Edge 


$\begin{array}{cl}\mathrm{Pt} & \text { Total Pressure } \\ \mathrm{Ps} & \text { Static Pressure } \\ \mathrm{Tt} & \text { Total Temperature } \\ \mathrm{Ts} & \text { Static Temperature } \\ \text { Mabs } & \text { Absolute Mach Number } \\ \text { Mrel } & \text { Relative Mach Number } \\ \mathrm{Cm} & \text { Meridional Velocity } \\ \mathrm{R} & \text { Blade Radius Location } \\ \text { Z } & \text { Blade Axial Location } \\ \text { k- } \omega-\mathrm{SST} & \text { K-Omega Turbulence Model } \\ \text { k- } \varepsilon & \text { k-Epsilon Turbulence Model } \\ \text { 3D } & \text { Three Dimensions } \\ \text { MEDUSA } & \text { Multiple Exhaust Duct with Source Adjustment } \\ \text { NACA } & \text { National Advisory Committee for Aeronautics }\end{array}$

\section{Introduction}

These days, the intrigue has all the more progressively been dedicated to the advancement of turbocharger as a result of their smaller size, vast limit, superior, and capacity to enhance volumetric effectiveness. The turbocharger is comprehensively utilized as a part of numerous applications, for example, marine diesel motors, vehicle motors, and little gas turbines for flying machine motors. The change of turbocharger turbine performance and the expansion of the stable working reaches are getting to be noticeably basic for the suitable eventual fate of low emanation motors. It is generally perceived that turbocharging is an extremely helpful strategy ordinarily connected in both spark-ignition and compression ignition motors to enhance motor productivity. Propelled advances, for example, factor geometry and multi-arrange turbocharging, high and low weight circle EGR frameworks, helped turbocharging and turbocompounding, are developing to control outflows and keep up efficiency in both diesel and gas motors. In addition, a powerful administration of the turbocharging framework gives the likelihood to accomplish an appropriate motor torque bend and an amazing vehicle driveability.

Also, the effect of clamor outflow have been anticipated in a semi 2D plan of car turbocharger turbines. The outcomes demonstrated that under low recurrence weight beats every one of the plans prompt comparative arrangements. However, for high recurrence throb the outcomes can be altogether different relying on the chose scheme(Galindo,2016). Another mass stream show is proposed in light of the physical model of an outspread turbine streamlined as two spouts in arrangement. The mass stream qualities of the turbocharger turbine is critical particularly when just a restricted scope of turbine information is given by manufacturers. The comes about demonstrated that considering the quantity of fitted coefficients and the displaying exactness, the derived model performs well in relapse examinations led with trial information tried from three spiral turbines of various sizes. Subsequently, this new model is adequately vigorous to display and extrapolate mass stream qualities of the outspread turbocharger turbine at off outline working conditions (Zhu,2015).

One of the key highlights that add to the difficulties in outlining exceptionally effective turbine is the intricate idea of the stream field inside the turbine organize itself. Thusly, the utilization of Computational Fluid Dynamics (CFD) in settling this issue is vital. This examination endeavors to give understanding on the multifaceted nature of 
stream point dispersion inside the turbocharger turbine organize. The Results demonstrated that despite the fact that utilization of guide vanes has decreased stream point vacillations at mid-traverse of the rotor delta from $\pm 10^{\circ}$ to just $\pm 1^{\circ}$, critical varieties still exist for speed parts in spanwise direction(Padzillah,2015 \& Capata,2014). Another fractional affirmation idea for turbocharger turbine operation at off-plan is composed and examined numerically and tentatively out of a turbocharger test fix. This new idea is called MEDUSA (Multiple Exhaust Duct with Source Adjustment) .The numerical outcomes demonstrated comparative misfortune instruments contrasted with a pivotal turbine organize, when fractional confirmation is connected. These outcomes showed an upgraded utilization of the accessible fumes enthalpy at part-stack conditions, accordingly enhancing the turbocharger performance at low end torque motor speeds (Ilievski,2015). The impact of the fumes gas turbocharger on nano-scale particulate matter (PM) number emanations from a Gasoline Direct Injected (GDI) motor is examined. Besides, a theory test additionally demonstrated that the effect of the turbocharger on add up to number outflows is factually significant paying little respect to the weakening proportion adopted (Cucchi , 2015 ).The turbocharger turbine beat stream performance forecasts are exhibited alongside a correlation of calculation length against the beforehand settled coordinated meanline technique. The consequences of expectation deviation showed that the mass stream rate and real power forecasts from the two techniques are profoundly practically identical and are sensibly near test data (Chiong,2015). The impact of vaned diffuser on an altered turbocharger radiating compressor performance, The outcomes were produced from CFD and were investigated for better comprehension of the liquid course through divergent compressor arrange and because of the stream in diffuser section has a tendency to be uniformity (Jawad, 2012, 2013 and 2014). One dimensional reenactment and test examination of a turbocharger turbine for car motors under unfaltering and precarious stream conditions, the general turbine performance delineate contrasted and the test one, demonstrated a decent agreement (Bellis , 2014). Demonstrating of a turbocharger turbine for automotive engines so as to assess the turbine performance in the entire working area, the numerical outcomes indicated great concurrence with the tentatively determined maps for all the tried devices (Bozza, 2014; Mohsin,2017). A trial think about was created to look at high and low weight fumes gas distribution frameworks (HP and LP EGR) fitted on a car turbocharged diesel motor. The outcomes watched patterns of fuel utilization, NOx and ash emanations as indicated by the weight charts and warmth discharge bends, as LP EGR and an alternate VGT position permitted diminishments of $2.1,50$ and $22.8 \%$ of these parameters (Zamboni ,2012 , 2013; Romagnoli , 2012).Characterization of a spiral turbocharger turbine in throbbing stream was considered numerically, the outcomes demonstrated that the stator spouts cause less aggregation impacts than the volute, yet show a little level of hysteretic conduct because of stream detachment and reattachment cycle around the vanes (Galindo, 2013) . Progressed numerical and experimental techniques for the extension of a turbine mapping were examined, The model henceforth demonstrates the possibility to defeated the restrictions of a traditional test-fix for a turbine mapping. The comes about are in addition approved against writing inferred 3D CFD reproduction findings (Bellis \& Chiong ,2013). Evaluation of unsteady flow effects on a nozzled turbocharger turbine was contemplated numerically. He precarious recreation is performed at settled 30000 RPM with $20 \mathrm{~Hz}$ beating flow (Padzillah , 2012 ). 
The unsteady performance of a double entry turbocharger turbine was examined The outcomes from these tests were then contrasted and precarious, in-eliminate and of-stage beat streams most illustrative of the real motor working condition(Copeland, 2012).

In the light of the certainties given over, the work detailed in this paper manages numerical examinations on the connection of vaned spout with an outspread turbine where CFD recreations and stream conduct of each a spiral turbine with vaned spout arrangements were performed. In this paper, the investigation is centered around the impact liquid stream dynamic into of a spiral turbine arrange on the turbocharger turbine performance to accomplish top notch stream and further performance change of the turbocharger turbine.

\section{Specifications and Design}

Once the impeller plan method has been finished, an illustration, both in 2D and 3D, was made. The 3-D geometry of the turbine (Figures 1 and 2) was made utilizing a devoted business programming (ANSYS Blademodeler), The variety of the beta edge ( $\beta$ ) along the rotor was build up by a spline bend for each layer (mid, center point and cover) that can be designed and changed in the program. The cutting edge profile decided for both, the rotor and stator, was a general NACA (National Advisory Committee for Aeronautics) profile. The turbine contemplated was an outspread turbine with spout organize demonstrate. The inflow and the surge of the liquid zone were as appeared in Figure 1. The fundamental geometry highlights and measurements of the adjusted compressor vaned diffuser and regular compressor are given in Table 1.

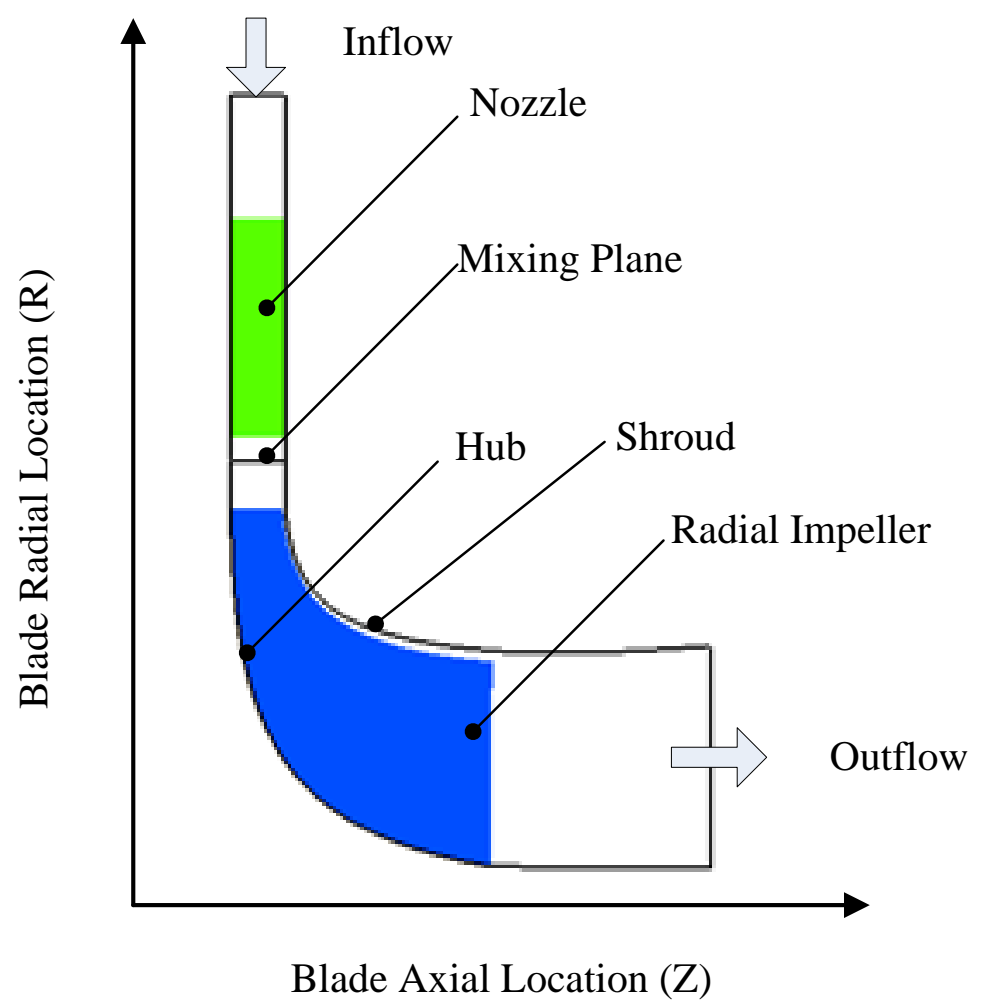

Figure 1: Impeller and Nozzle on the Meridional View 
Table 1: Radial Turbine And Nozzle Features.

\begin{tabular}{lc}
\hline Radial Turbine Geometry & Rotor \\
\hline Impeller Axial Width & $42 \mathrm{~mm}$ \\
Turbine Inner Radius at Inlet & $18.7 \mathrm{~mm}$ \\
Turbine Outer Radius at Inlet & $53.5 \mathrm{~mm}$ \\
Outer Radius of Impeller & $76.37 \mathrm{~mm}$ \\
Width of Impeller at Leading Edge & $9 \mathrm{~mm}$ \\
Blades Number & 9 \\
Shroud Tip Clearance (\% span) & $95 \%$ \\
\hline Nozzle Geometry & Stator \\
\hline Nozzle Vanes Number & 18 \\
Inner Radius of Nozzle & $87.8 \mathrm{~mm}$ \\
Outer Radius of Nozzle & $122.95 \mathrm{~mm}$ \\
Inner Axial Width of Vane & $9 \mathrm{~mm}$ \\
\hline
\end{tabular}

Figure 2 demonstrates the geometry of an radial turbine wheel vaned nozzle organize including nine primary impeller cutting edges and 18 nozzle vanes. The computational fluid dynamic calculations for the design were performed on the geometries.

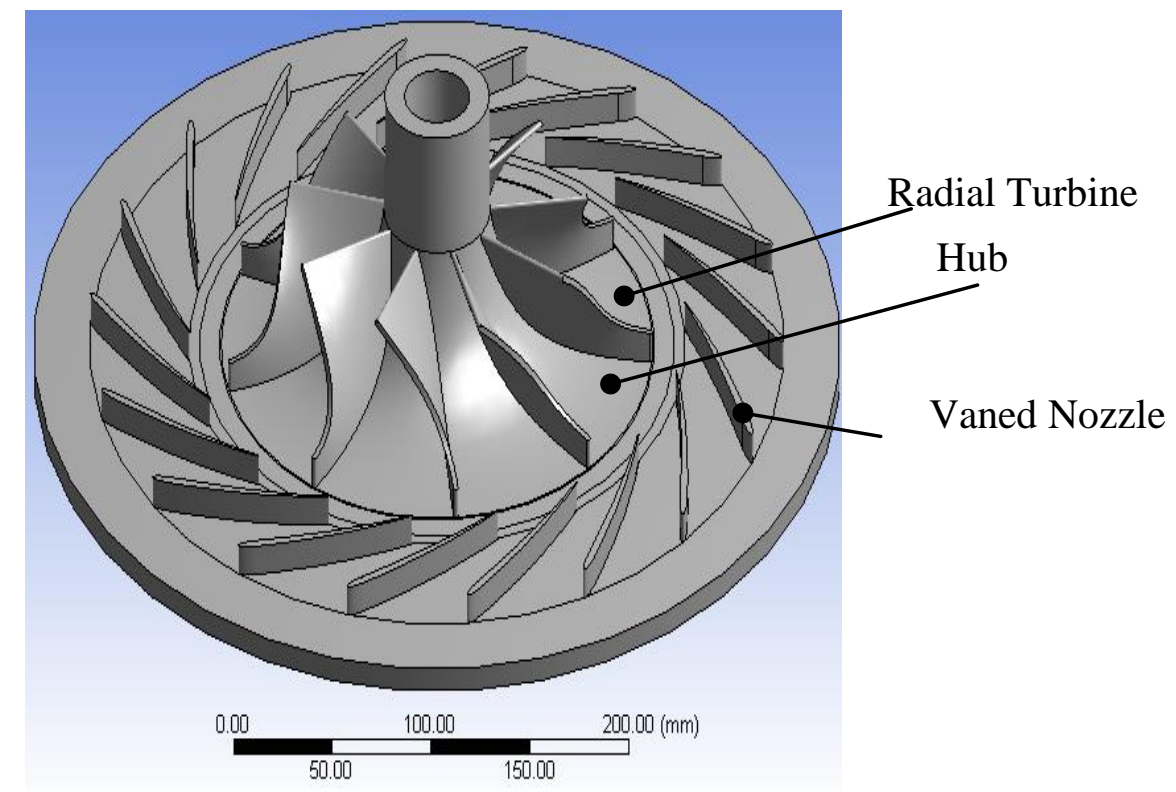

Figure 2: Three Dimensional View of a Radial Turbine stage

\section{Computational Fluid Dynamic Methodology}

\subsection{Generation of Mesh}

A CFD code was utilized to complete the numerical analysis. The fluid area was separated for one impeller cutting edge section with the edge itself amidst the space .The surface work is produced by utilizing a hexahedral work on the impeller and vane surfaces. The surface repair instruments have adequate control to permit the examination 
by picking among the parts to incorporate and avoid in the cross section. This is to control the extent of work in different parts by utilizing the surface ebb and flow or by characterizing neighborhood refinement zones. Once these surface work control settings are characterized, the instrument holds the relationship with the foreign CAD parts. This makes parametric demonstrating of the segments simple. The limited component work is created by utilizing hexahedral, as approved for stream and warm arrangements. The hexahedral component work comprises of 8 hubs, agglomerated from the basic consequently produced hexahedral work. Hexahedral networks offer huge favorable circumstances over customary work sorts. The computational framework, for the impeller edge section containing precisely 432826 organized hexahedral components in multisquare condition and for the vaned spout entry including 319625 hexahedral components were created utilizing a committed programming (ANSYS Turbogrid) the measure of layers and components work information is appeared in table 2. Adequately fine network components were made in the impeller tip freedom area, around the impeller, and at the center point and cover dividers. Adequate work quality checks were performed by keeping the parameters like work point and determinants inside worthy cutoff points.

Table 2: CFD Mesh Data of Air Ideal Gas

\begin{tabular}{cccc}
\hline & No. of layers & No. of Nodes & No. of Elements \\
\hline Stator & 2 & 344812 & 319625 \\
Rotor & 3 & 463900 & 432826 \\
Total & - & 808712 & 752451
\end{tabular}

The size of mesh plays an essential part in solution for both accuracy. A coarse mesh is initially used to quickly test the solver settings. Better meshes, in general, make the solution independent of the grid size and produce further accurate results but continuously need lager computational resources and time. Thus, a settlement between the grid size on one hand and convergence and accuracy on the other hand is essential. Hence, a grid independence study was carried out to guarantee that the numerical solutions are grid-independent. Hence, a fine grid size of elements was used for the computational fluid dynamic calculation reported in this paper. Figure 3 shows the computational domain at ANSYS CFX, the figure shows the surface grid for the computational domain. 

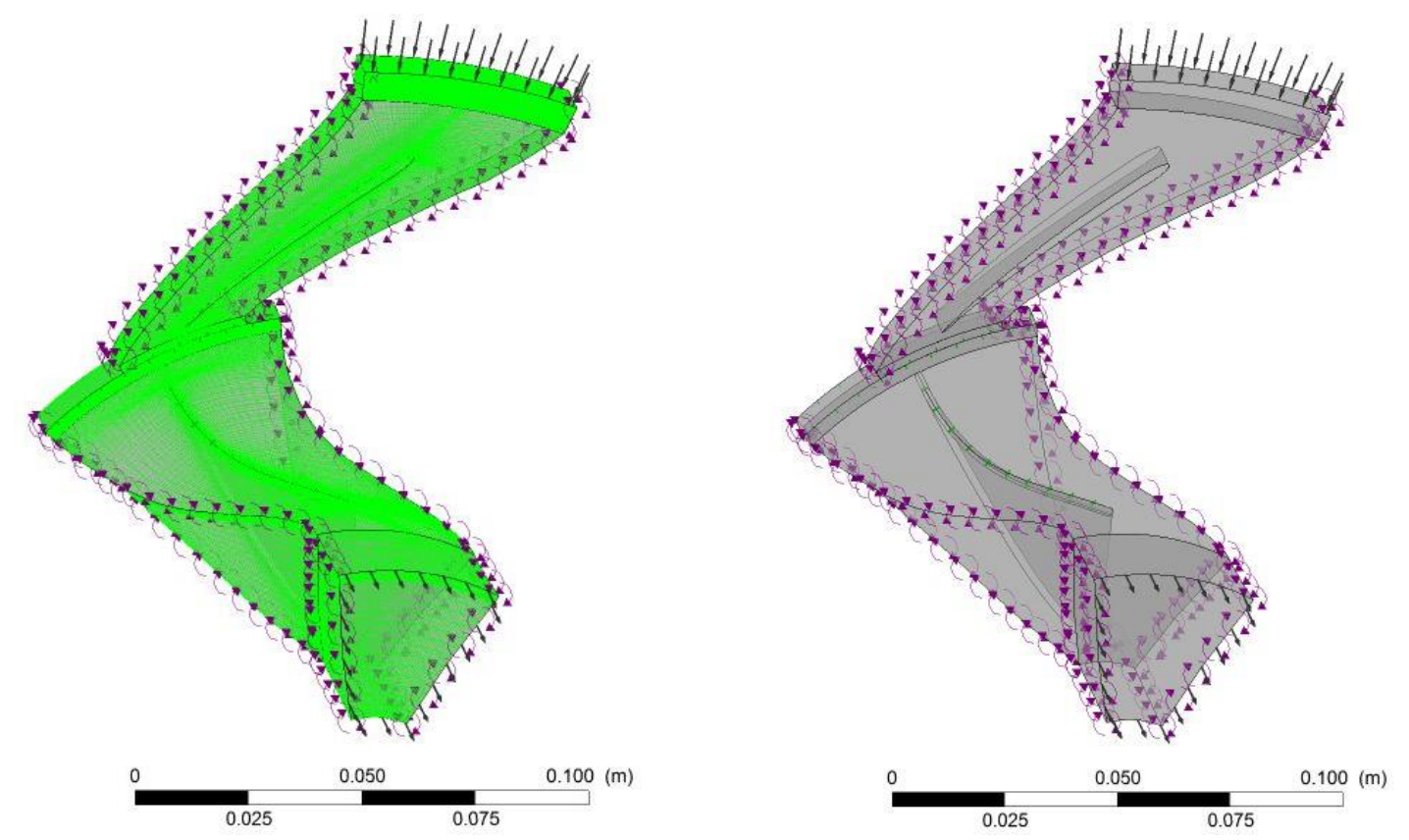

Figure 3: Surface grid for the computational domain

\subsection{Modelling of Fluid Flow}

The Parametric calculations were performed on a three dimensional-Turbulent CFD to get the performance of backswept impeller setups. The fluid zone involves one zone wrapping all the turning parts (hub and blades ) and the other region of the stationary parts (inlet, outlet, shroud and vaned nozzle). The left and right limits are characterized as periodic. Turbulence is demonstrated utilizing the k- $\omega$-SST show. This model is a zonal mix of k- $\omega$ close to the divider, ostensibly in the limit layer, and $k-\omega$ far from the dividers. At the point when the close divider work is good with the divider work approach, this model carries on dominatingly as a high-Reynolds number k- $\omega$ plan. All surfaces are dealt with as adiabatic. Add up to weight and aggregate temperature are connected to the inflow delta limit. The outpouring outlet condition is set to static weight. The limit conditions utilized for a spiral turbine configuration are recorded in table 3 .

Table 3: Boundary Conditions Used in CFD Calculations.

Total temperature at domain inlet (Kelvin)

Total pressure at domain inlet (bar)

Flow angle at domain inlet (degree)

Rotational speed (rpm)

Exit static pressure (bar)

Physical Timescale

Stator's Outlet-Rotor's Inlet

Flow Direction
845

3.45

(0) Radial Direction 50000

1.03

0.00002

General Connection (Stage)

Cylinderical $(0,-1,0)$

\section{Results and Discussion}

The numerical technique utilized by the solver part of the product requires an iterative procedure so as to acquire an answer. All in all, the remaining magnitude should diminish as the solution converges. At the point when the size of the residuals for every 
one of the amounts falls underneath the convergence level, the solver will quit emphasizing, and the outcomes will be traded for post-preparing. In Table 4 the overall performance prediction for the designed a radial turbine machine when running at the design point as indicated from the CFD results.

The blade loading was checked to make sure that the flow is not forced to reverse direction near the trailing edge. Figure 4 shows the blade loading through the rotor passage at $50 \%$ span. The red circle is the region where the flow is usually forced to reverse direction because the pressure at suction surface becomes larger than that on the pressure surface. This pressure reversal causes losses in the turbine, so in this design this reversal in the pressure can be avoided.

Figure 5 illustrations the vector and velocity contours and at different of turbine rotor span and stator. No separation was detected at the design point; the nozzle vanes angle and number of rotor blades were iterated a number of times to avoid flow separation which is a major source of loss.It can be seen that typical behavior of the fluid going through an impeller, which is a low speed stream in the pressure section of the impeller and a high speed stream on the suction segment of the impeller. The speed vector size at the mid spanwise area for impeller vaned nozzle arrangements from the nozzle inlet and impeller exit impeller noticeably uniform. Along these lines, the losses of flow diminish while the efficiency and pressure ratio becomes higher.

In addition, the contour of Mach number and pressure at different spanwise location for a rdail impeller and vaned nozzle configurations from the vaned nozzle inlet to impeller exit, as an example of CFD computations as shown in Figure 6. It can be seen no choke of flow at the inlet of the designed type because of the uniform distribution of the throat area between blade to blade passages. It can be seen the flow in the space area between the trailing edge of the vane nozzle, and the leading edge of the impeller turbine which is close to Mach one meaning the space area ratio which is a very important factor to modify in order to remove any choking of the flow for all configurations . It is clearly seen that the effect of flow vaned angle to increase and decrease the backflow vortex. High-pressure can be noted on the stator leading edge due to the flow impact with the blade that is a normal behavior.

Moreover, Figure 7 shows the Mach number on a meridional surface of the impeller vaned nozzle from the inlet to outlet location. It is clearly seen that the Mach number is lower than one and there is no chocking of flow. the contour of meridional velocity from Leading Edge (LE) of vane to Trailing Edge (TE) of impeller clearly seen along a meridional length from inlet vane to impeller exit. Moreover, It can be seen that the high velocity is located in the space between the vane exit and impeller inlet. As earlier mentioned that the space area ratio which is a very important factor to modify.The contour of pressure difference on the meridional surface of the impeller vaned nozzle from the inlet to outlet location, obviously seen that the effect of the inlet to outlet of the distribution of pressure, it can be seen evidently the effect of vaned nozzle to guide the flow. Therefore, the contour temperature behavior in the simulation is smooth during the calculations.

Figure 8 illustrations the across the streamwise location the Mach number difference, from the inlet vaned nozzle to the outlet impeller; it is obviously seen that Mach number is higher at the space between the vane exit and impeller inlet; consequently, it is very significant to take into account the impact of a space ratio in the 
design.CFD models give a much deeper understanding of the flow inside a radial turbine vaned nozzle, enabling us to solve many problems easily and rapidly. The numerical analysis was carried out including the impeller vaned nozzle flow passage only. The modification of a previous design of a radial turbine impeller provides a wide operating range or a better performance.

Table 4: Overall Performance Results

\begin{tabular}{lc}
\hline Mass Flow Rate $(\mathrm{kg} / \mathrm{s})$ & 1.3142 \\
Shaft Power $(\mathrm{W})$ & 247788 \\
Inlet Flow Coefficient & 0.7618 \\
Total Pressure Ratio & 3.3331 \\
Total Temperature Ratio & 1.2881 \\
Nozzle Loss Coefficient & 1.7882 \\
Nozzle Efficiency \% & 92.1491 \\
T-T isen. Efficiency\% & 0.811605 \\
T-S isen. Efficiency\% & 0.660572 \\
T-T poly. Efficiency\% & 0.785733 \\
T-S poly. Efficiency\% & 0.612412
\end{tabular}

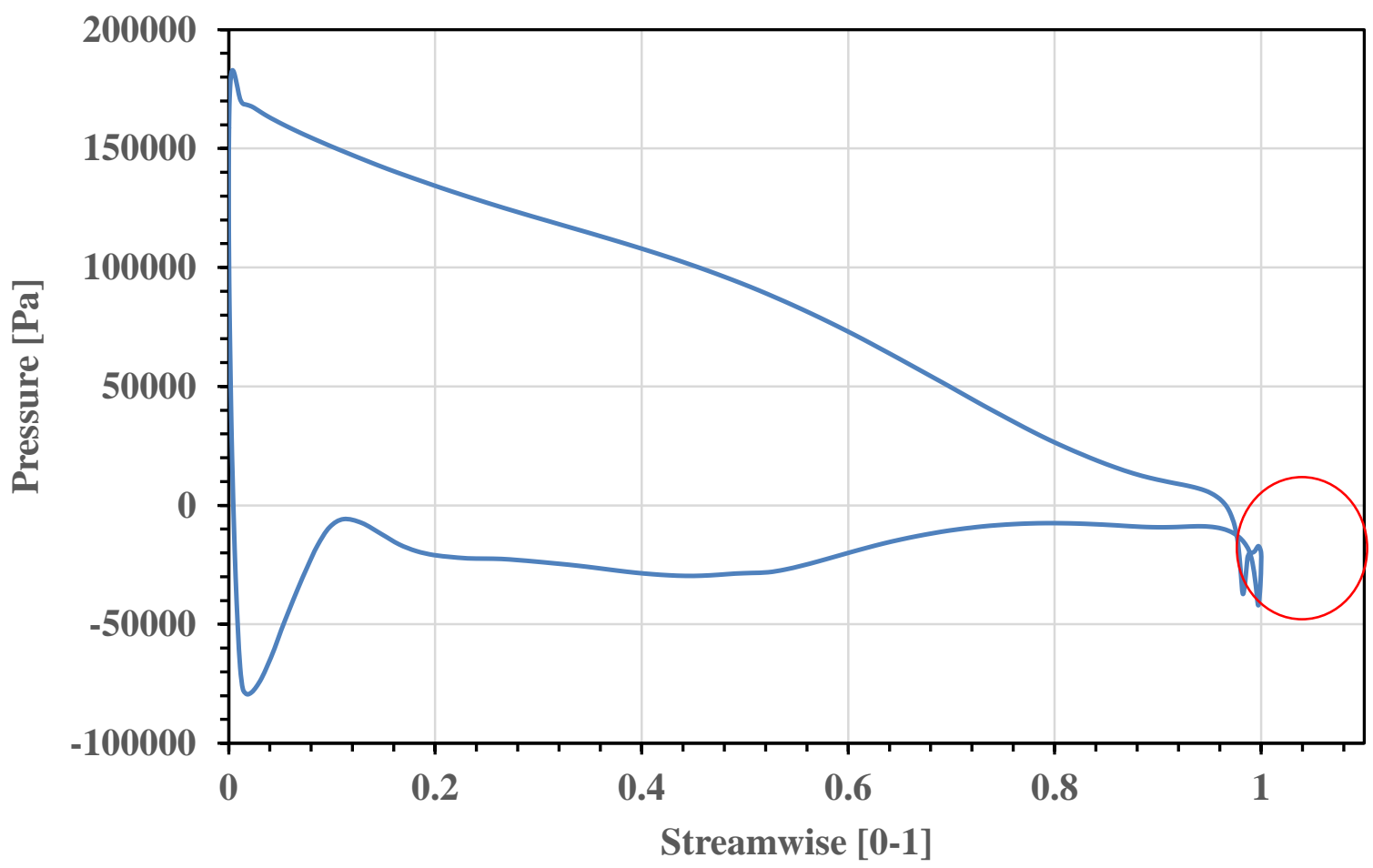

Figure 4: Rotor wheel blades loading 


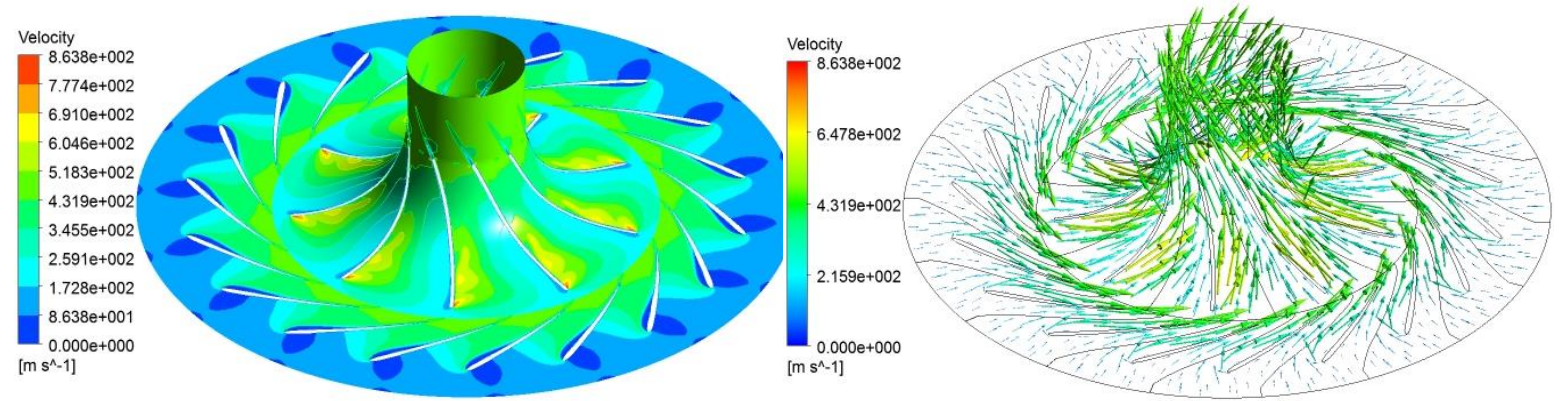

Spanwise $20 \%$
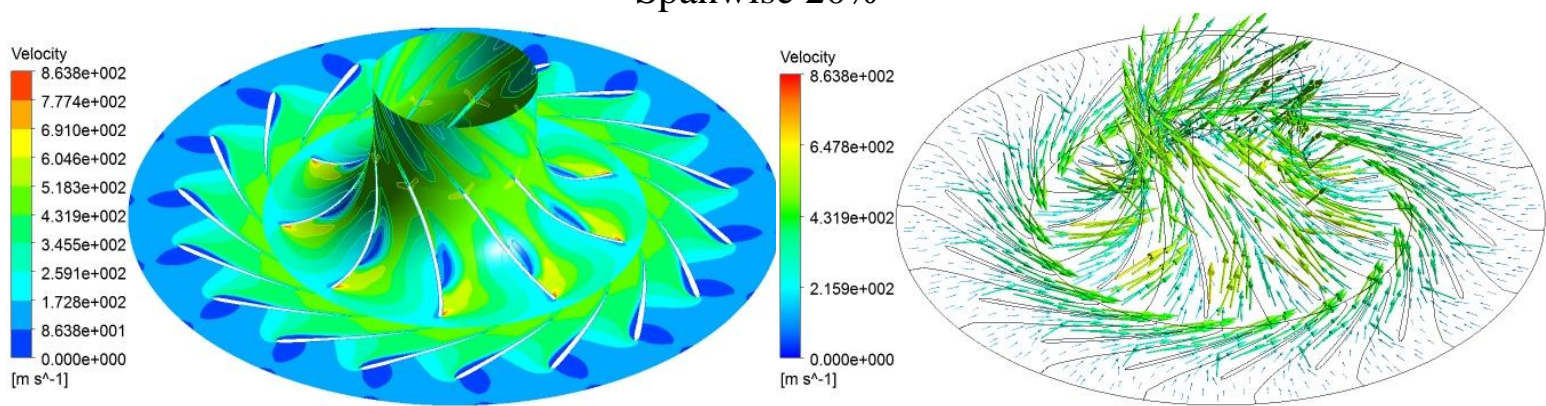

Spanwise 50\%
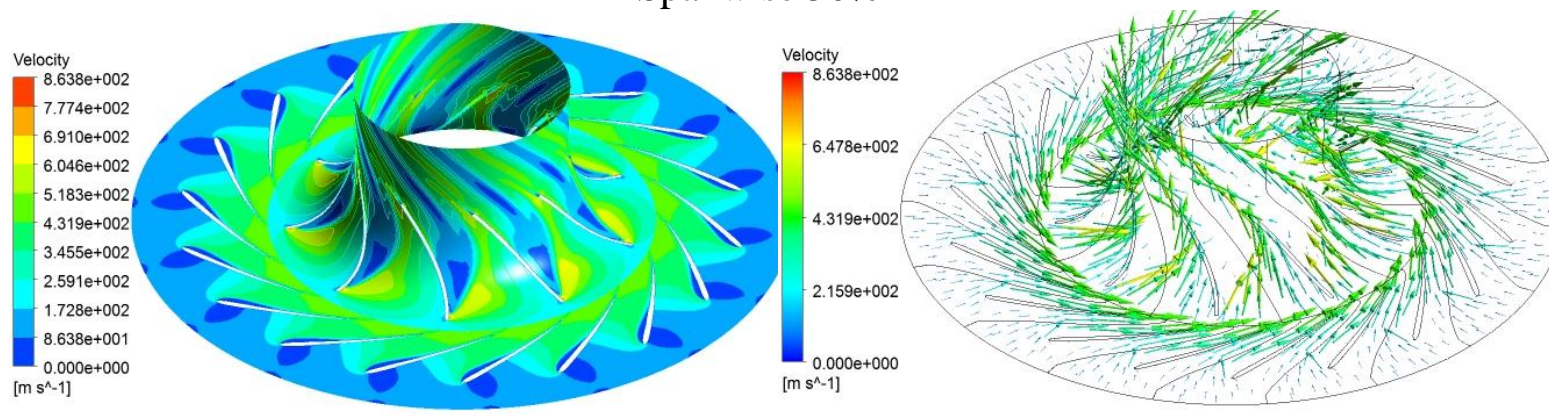

Spanwise $80 \%$

Figure 5: Velocity Contours and Vectors for Different Span 

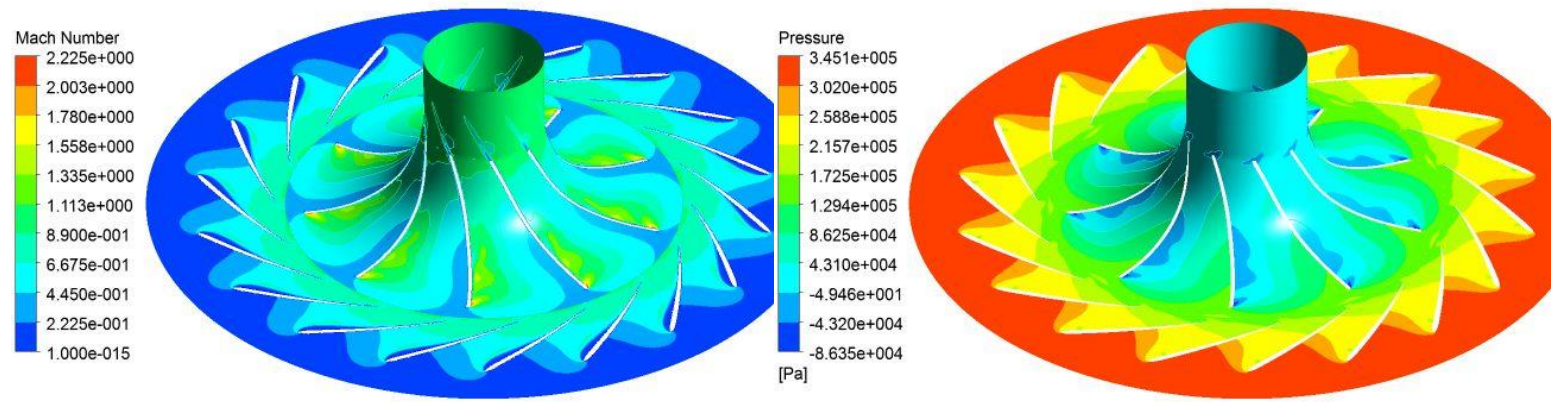

Spanwise $20 \%$
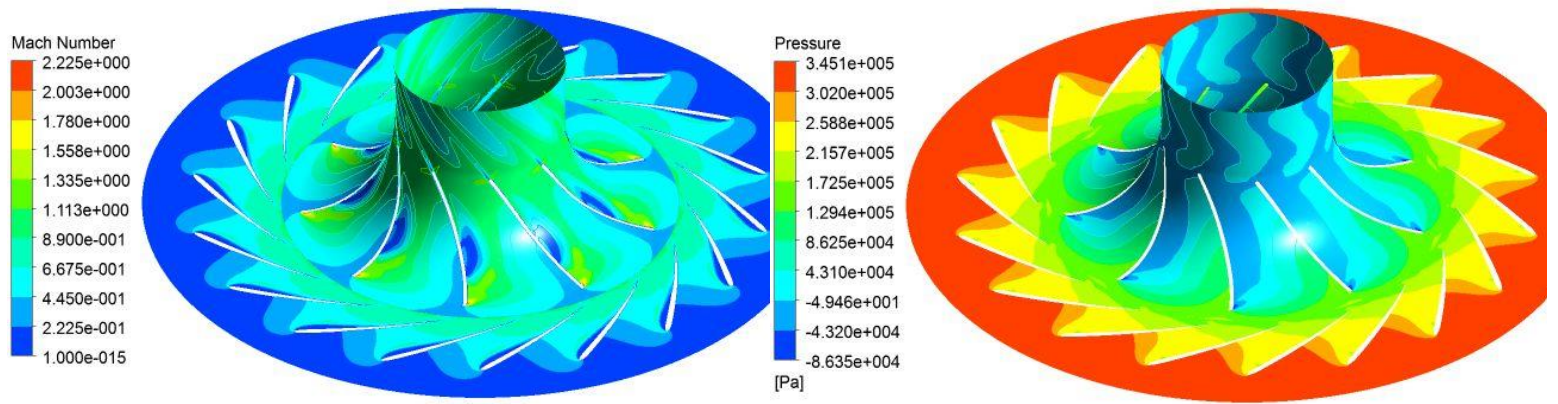

Spanwise $50 \%$
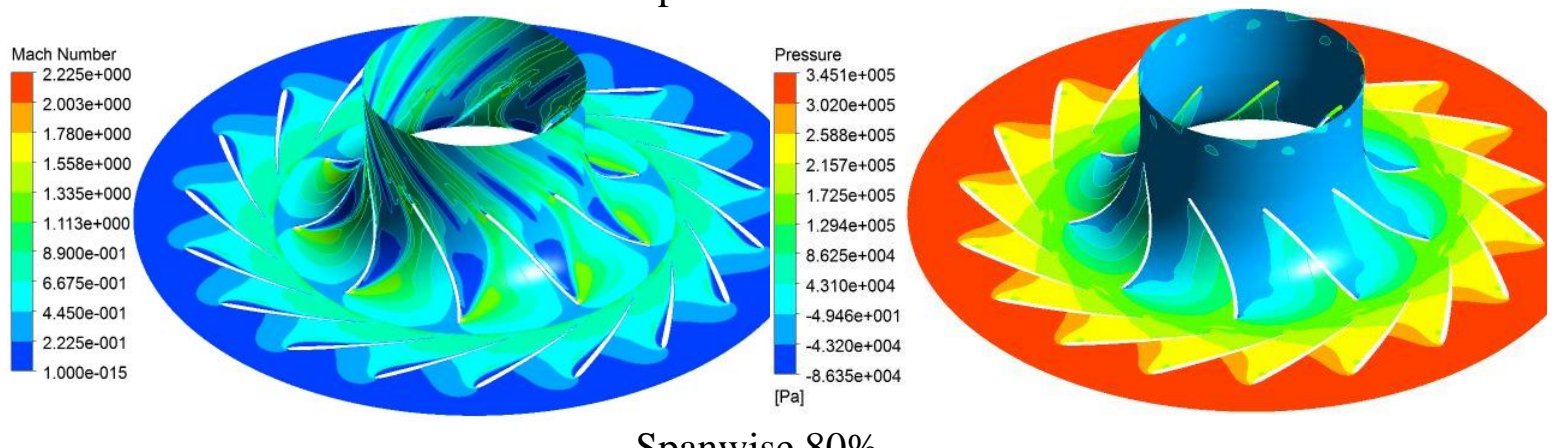

Spanwise $80 \%$

Figure 6: Mach Number and Pressure Contours for Different Span 

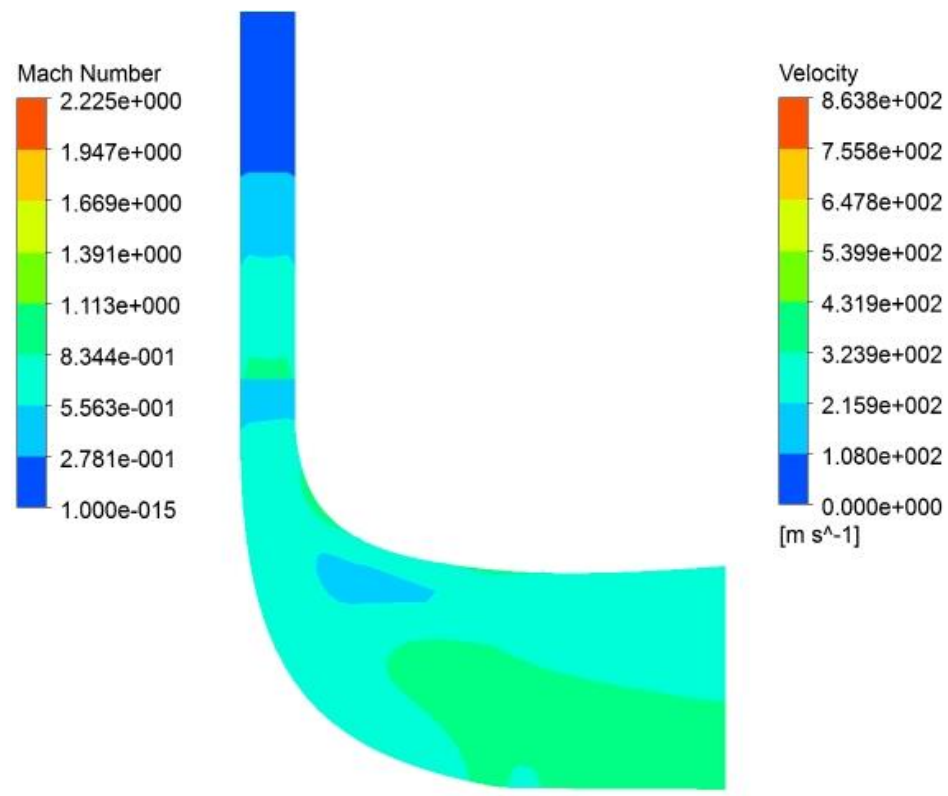
$\left[\mathrm{m} \mathrm{s}^{\wedge}-1\right]$
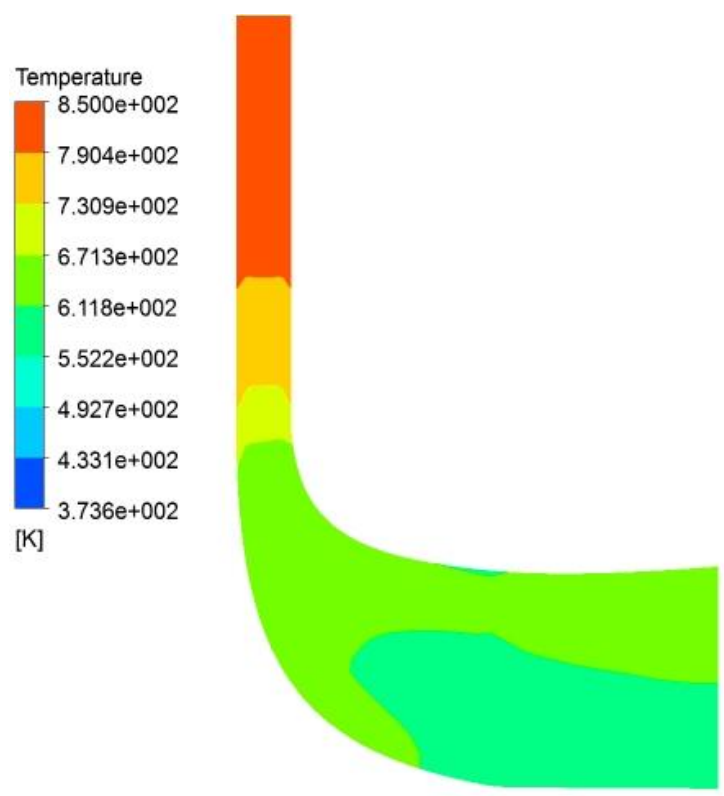
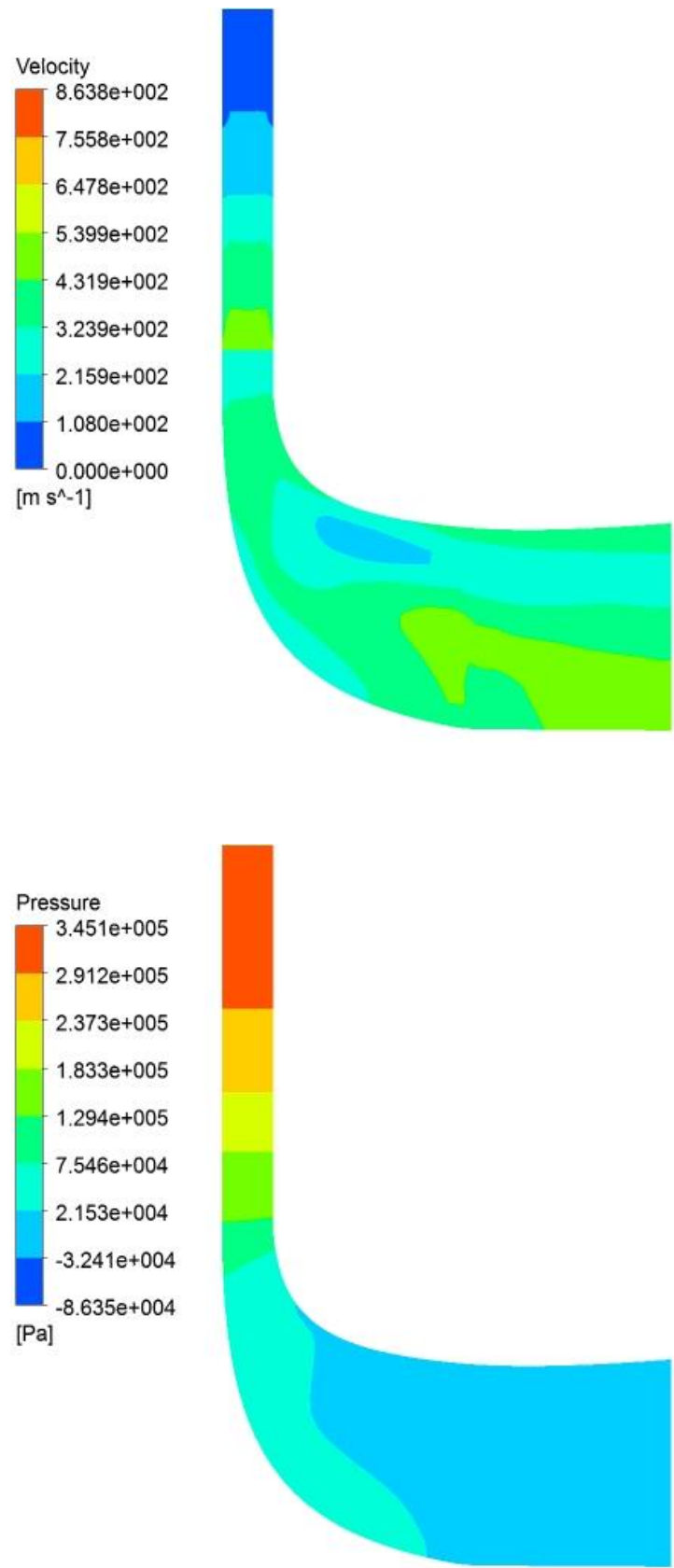

Figure 7: Contour of Meridional Mach Number,Velocity,Temperature and Pressure on Meridional Surface 


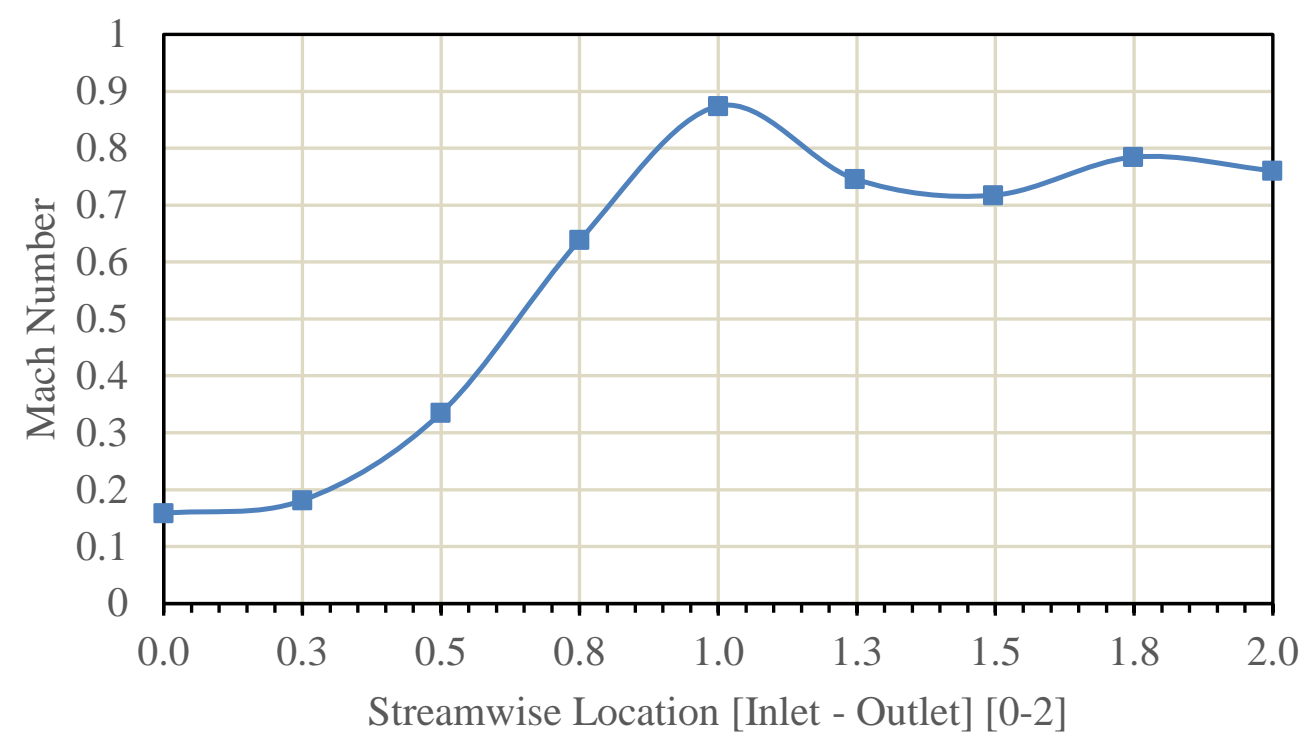

Figure 8: Inlet to Outlet Streamwise Location with Mach number

\section{Conclusions}

The downsizing trends is a major concern for turbocharger development in current car engines. In any case, the coordinating between a radial impeller and nozzle vanes is troublesome, along these lines computational fluid dynamics have a more prominent influence in the of turbomachinery aerodynamic design. For a long time the design of a modern compressoror turbine has been unbelievable without the assistance of computational fluid dynamics. The advantages of CFD extend from shorter design cycles to better performance and decreased expenses and weight. Steady state flow simulation have been conducted so as to analyse, the effects of the interaction vaned nozzle on the turbine performance are systemically simulated and analyzed. The investigation of the flow features was also accomplished to acquire a better understanding of the flow behaviours for blade to blade vaned nozzle turbine, at a certain speed it was 50k RPM. The following conclusions are obtained; firstly, CFD simulation be able to predict and improve the performance of a radial turbine. Secondly, the radial direction flow of the nozzle meridional passage is squeezed. The vortex and backflow near the pressure surface regularly disappear. The flow tends to be uniform; hence the total pressure ratio and efficiency are both enhanced. An effort was made to model the flow from the inlet to the exit of a radial turbine stage consisting of all the components in place using computational fluid dynamics tools. The contour, vector and Streamline plots are produced for better understanding of fluid flow through the a radial turbine stage. Conclusively, the aerodynamic results display that the performance was pointedly affected by meridional passage of a radial turbine and nozzle vanes.

\section{References}

Bozza F. and De Bellis V. ,2014, "Steady modeling of a turbocharger turbine for automotive engines," Journal of Engineering for Gas Turbines and Power, vol. 136, p. 011701. 
Capata R. and Hernandez G. ,2014, "Preliminary design and simulation of a turbo expander for small rated power organic Rankine cycle (ORC)," Energies, vol. 7, pp. 7067-7093.

Chiong M. et.al., 2015 , "Non-adiabatic pressure loss boundary condition for modelling turbocharger turbine pulsating flow," Energy Conversion and Management, vol. 93, pp. 267-281.

Chiong M. S. et.al.,2013 , "Assessment of Cycle Averaged Turbocharger Maps Through One Dimensional and Mean-line Coupled Codes," in ASME Turbo Expo 2013: Turbine Technical Conference and Exposition, pp. V06CT40A026-V06CT40A026.

Copeland C. D. et.al. ,2012, "Unsteady performance of a double entry turbocharger turbine with a comparison to steady flow conditions," Journal of Turbomachinery, vol. 134, p. 021022.

Cucchi M. and Samuel S., 2015 ,"Influence of the exhaust gas turbocharger on nano-scale particulate matter emissions from a GDI spark ignition engine," Applied Thermal Engineering, vol. 76, pp. 167-174.

De Bellis V. et.al., "1d simulation and experimental analysis of a turbocharger turbine for automotive engines under steady and unsteady flow conditions," Energy Procedia, vol. 45, pp. 909-918.

De Bellis V., et.al.,2013 , "Advanced numerical and experimental techniques for the extension of a turbine mapping," SAE International Journal of Engines, vol. 6, pp. 1771-1785.

Galindo J., et.al. ,2016, "Effect of the numerical scheme resolution on quasi-2D simulation of an automotive radial turbine under highly pulsating flow," Journal of Computational and Applied Mathematics, vol. 291, pp. 112-126.

Ilievski M. et.al. ,2015 , "Experimental and Numerical Investigation of Partial Admission of a Radial Turbocharger Turbine for Improved Off-Design Operation," in ASME Turbo Expo 2015: Turbine Technical Conference and Exposition, pp. V008T23A018-V008T23A018.

Jawad L. H. et.al.,2012 , "Modelling of Centrifugal Compressor Impellers Using Adaptive Neuro- Fuzzy Inference Systems(ANFIS)," International Review of Mechanical Engineering, vol. 6, pp. 1011-1017.

Jawad L. H. et.al. ,2013, "Numerical Investigation on the Effect of Impeller Trimming on the Performance of a Modified," CFD Letters, vol. 5, pp. 174-184.

Jawad L. H. et.al. , 2014, "Effect of Vaned Diffuser on a Modified Turbocharger Centrifugal Compressor Performance," Applied Mechanics \& Materials.

Jawad L. H., et.al. ,2014, "Numerical study on the effect of interaction vaned diffuser with impeller on the performance of a modified centrifugal compressor," Journal of Mechanics, vol. 30, pp. 113-121.

Mohsin Obaid Muhi ,2017," Numerical Prediction of an Axial Turbine Performance Used for Automotive Engines Turbocharger". Journal of Babylon University/Engineering Sciences No.(5) Vol.(25).

Padzillah M. et.al. ,2015 , "Experimental and numerical investigation on flow angle characteristics of an automotive mixed flow turbocharger turbine," Jurnal Teknologi, vol. 77. 
Padzillah M., et.al., 2012 , "Numerical assessment of unsteady flow effects on a nozzled turbocharger turbine," in ASME Turbo Expo 2012: Turbine Technical Conference and Exposition, pp. 745-756.

Romagnoli A. and Martinez-Botas R. ,2012, "Heat transfer analysis in a turbocharger turbine: An experimental and computational evaluation," Applied Thermal Engineering, vol. 38, pp. 58-77.

Zamboni G. and Capobianco M. ,2013, "Influence of high and low pressure EGR and VGT control on in-cylinder pressure diagrams and rate of heat release in an automotive turbocharged diesel engine," Applied Thermal Engineering, vol. 51, pp. 586-596.

Zamboni G.and Capobianco M. ,2012, "Experimental study on the effects of HP and LP EGR in an automotive turbocharged diesel engine," Applied Energy, vol. 94, pp. 117-128.

Zhu S. et.al. ,2014, "Modeling and extrapolating mass flow characteristics of a radial turbocharger turbine," Energy, vol. 87, pp. 628-637, 2015. 